\title{
Beta3-Tubulin Is Critical for Microtubule Dynamics, Cell Cycle Regulation, and Spontaneous Release of Microvesicles in Human Malignant Melanoma Cells (A375)
}

\author{
Mohammed O. Altonsy ${ }^{1,2}{ }^{-}$, Anutosh Ganguly ${ }^{1,3,4}$, Matthias Amrein ${ }^{5}$, Philip Surmanowicz ${ }^{1}$, \\ Shu Shun Li ${ }^{3}$, Gilles J. Lauzon ${ }^{1}$ and P. Régine Mydlarski ${ }^{1, *}$ \\ 1 Division of Dermatology, Department of Medicine, University of Calgary, Calgary, AB T2T 5C7, Canada; \\ mohammedomarahmed.mo@ucalgary.ca (M.O.A.); ganutosh@umich.edu (A.G.); \\ philip.surmanowicz@gmail.com (P.S.); glauzon@ualberta.ca (G.J.L.) \\ 2 Department of Zoology, Faculty of Science, Sohag University, Sohag 82524, Egypt \\ 3 Department of Microbiology, Immunology and Infectious Diseases, University of Calgary, \\ Calgary, AB T2N 4N1, Canada; shusli@ucalgary.ca \\ 4 Department of Surgery, University of Michigan, Ann Arbor, MI 48105, USA \\ 5 Department of Cell Biology and Anatomy, University of Calgary, Calgary, AB T2N 4N1, Canada; \\ mamrein@ucalgary.ca \\ * Correspondence: regine.mydlarski@ucalgary.ca; Tel.: +1-403-955-8345; Fax: +1-403-955-8200
}

Received: 6 February 2020; Accepted: 25 February 2020; Published: 28 February 2020

\begin{abstract}
Microtubules (MTs), microfilaments, and intermediate filaments, the main constituents of the cytoskeleton, undergo continuous structural changes (metamorphosis), which are central to cellular growth, division, and release of microvesicles (MVs). Altered MTs dynamics, uncontrolled proliferation, and increased production of MVs are hallmarks of carcinogenesis. Class III beta-tubulin ( $\beta 3$-tubulin), one of seven $\beta$-tubulin isotypes, is a primary component of MT, which correlates with enhanced neoplastic cell survival, metastasis and resistance to chemotherapy. We studied the effects of $\beta 3$-tubulin gene silencing on MTs dynamics, cell cycle, and MVs release in human malignant melanoma cells (A375). The knockdown of $\beta 3$-tubulin induced G2/M cell cycle arrest, impaired MTs dynamics, and reduced spontaneous MVs release. Additional studies are therefore required to elucidate the pathophysiologic and therapeutic role of $\beta 3$-tubulin in melanoma.
\end{abstract}

Keywords: melanoma; $\beta 3$-tubulin; microtubules; microvesicles

\section{Introduction}

Class III beta-tubulin ( $\beta 3$-tubulin), encoded by the TUBB3 gene, is one of seven beta-tubulin isotypes in the human genome. It is constitutively expressed in neurons of the peripheral and central nervous system, regulating neuronal differentiation and development [1]. Microtubules (MTs), which comprise the cytoskeleton in almost all eukaryotic cells [2], are assembled through the dimerization of $\alpha$ - and $\beta$-tubulin proteins [3]. The dynamics of MTs, which involve phases of elongation, shortening, and pause [4], are relevant to intracellular trafficking, the formation of the mitotic spindle, cytokinesis, cell membrane blebbing, cell migration, and phagocytosis [2,5-7].

Microvesicles (MVs) are secreted by intact cells as microscopic membrane-enclosed sacs ranging in diameter from 100 to $1000 \mathrm{~nm}$. They are formed by plasma membrane protrusions (buds), which then close and become separated from the progenitor cell, eventually to be released into the extracellular environment [8,9]. MVs are distinguished from the more homogeneous exosomes (40-100 nm), which are formed intracellularly within microvesicular bodies, and are thus of endosomal origin $[10,11]$. 
Membrane-bound proteins and luminal content determine the MV's function, which consequently relates to the cell of origin [9,12]. Melanoma cell-derived MVs are postulated to play a biological role in the process of carcinogenesis. For example, malignant transformation of melanocytes is associated with the increased production and release of MVs with procoagulant activity, leading to a hypercoagulable state, a major cause of death in cancer patients $[13,14]$. Murine melanoma cell-derived MVs promote metastasis and immunosuppression through regulatory T-cell expansion and apoptosis of tumor-specific $\mathrm{CD} 8^{+}$cytotoxic T-cells, effects mediated by the MV-associated Fas ligand or TRAIL [15].

Furthermore, the remote delivery of peripheral mast cells originated-MVs to lymph nodes via the lymphatics would allow for more systemic modulation of inflammation and immunosuppression [10]. A similar mechanism may be involved in the invasion of melanoma cells into the dermis. Overall, MVs are postulated to promote cancer initiation, survival, and spread $[12,13,16]$. Herein, we hypothesize that $\beta 3$-tubulin interferes with microtubule dynamics, cell cycle regulation, and the spontaneous release of MVs in A375 human malignant melanoma cells.

\section{Results}

\subsection{A375 Cells Express $\beta 3$-Tubulin $m R N A$ and Protein}

$\beta 3$-tubulin is highly expressed in malignant as compared with normal melanocytes, and siRNA knockdown of $\beta 3$-tubulin hinders the migration of melanoma cells [17]. Using RT-PCR and Western blot analysis, we demonstrated that the A375 human malignant melanoma cells express $\beta 3$-tubulin mRNA and protein (Figure 1A). siRNA knockdown of $\beta 3$-tubulin significantly reduced the mRNA and protein expression by $79.3 \% \pm 7.7 \%(p<0.001)$ and $83 \% \pm 4.9 \%(p<0.01)$, respectively. The effect of treatment with either $\beta 3$-tubulin siRNA or control siRNA on the immunostaining of melanoma cells A375 with both $\beta 3$-tubulin and a specific molecular marker for melanoma cells (melanoma-associated antigen, or MAA) confirmed the specificity of $\beta 3$-tubulin knockdown by $\beta 3$-tubulin siRNA (Figure 1B and Figure S1), with no observed effect on cell viability assessed by an MTT assay (Figure 1C).

\section{2. siRNA Knockdown of $\beta 3$-Tubulin Reduces the Spontaneous Release of MVs by A375 Cells}

The spontaneous release of MVs by A375 cells was assessed using Alexa fluor 488-labeled wheat germ agglutinin (WGA) to stain cell membranes, followed by fluorescence microscopy. A375 cells release ring-like MVs with clear intravesicular spaces with sizes ranging from 200 to $1000 \mathrm{~nm}$ (Figure 1F). MVs were also detected in the culture medium (Figure 1G). The effect of $\beta 3$-tubulin knockdown on MVs counts was assessed by flow cytometric quantification of MAA-labeled MVs in the culture media of naïve, control-, and $\beta 3$-tubulin siRNA-treated cells. Knockdown of $\beta 3$-tubulin induced a significant $48.63 \%(p<0.001)$ reduction of released MVs, relative to naïve cells (Figure 1D,E), while control siRNA did not affect MVs release from cells. These data demonstrate that $\beta 3$-tubulin modulates, at least in part, spontaneous MVs release from A375 melanoma cells.

\section{3. siRNA Knockdown of $\beta 3$-Tubulin Suppresses MTs Dynamics and Induces G2/M Cell Cycle Arrest}

Altered cellular MTs dynamics, including elongation, shortening, and a pause, are salient to carcinogenesis, broad-spectrum chemotherapy resistance and cell survival [18]. The effect of $\beta 3$-tubulin knockdown on MTs dynamics in A375 cells transfected with EGFP-microtubule-associated protein-4 cDNA (EGFP-MAP4) was assessed. A sequence of frames, five-second apart, of the life-history of MTs +ends transitioning between phases of elongation (growth), shortening, and pause is shown (Figure 2A). MTs +end displacements (growth/shortening) of naïve and control siRNA-treated cells were greater than those of $\beta 3$-tubulin knockdown cells (Figure 2A, Figure S2, and Table S1). The rate of total growth and total shortening were reduced by $39.7 \% \pm 5 \%(p<0.001)$ and $52 \% \pm 4.7 \%$ $(p<0.001)$, respectively, in $\beta 3$-tubulin knockdown cells as compared to naïve cells, whereas control siRNA treatment had no effect on these parameters. Further, pause frequency was significantly higher 
in $\beta 3$-tubulin knockdown cells by $19.04 \% \pm 4.2 \%(p<0.05)$, whereas overall MTs dynamicity was significantly reduced by $46.53 \% \pm 4.3 \%(p<0.001)$.

(A)

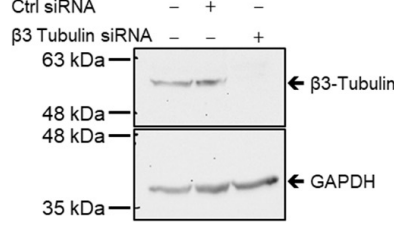

(B)

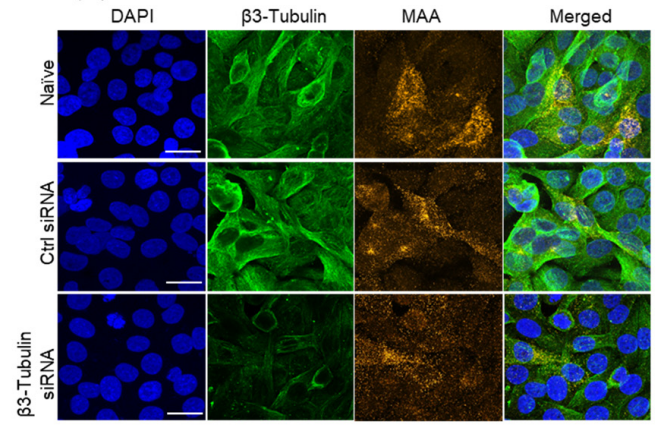

(C)

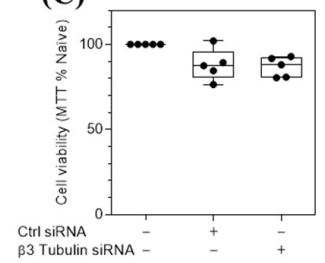

(D)

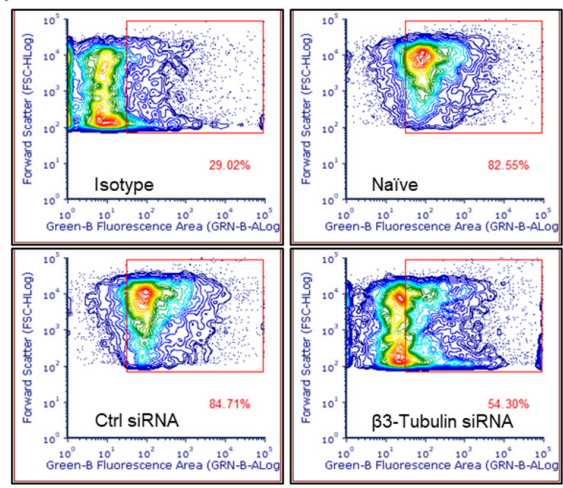

(E)

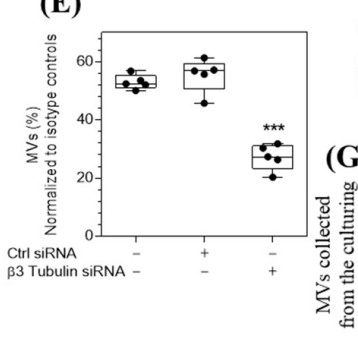

(F)

(F) WGA staining

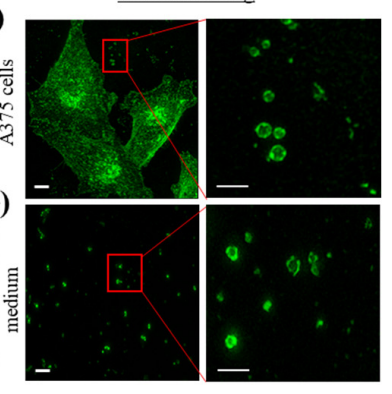

Figure 1. $\beta 3$-tubulin knockdown reduces the numbers of microvesicles (MVs) spontaneously released by A375 melanoma cells under the standard culture conditions. (A) Western blots of $\beta 3$-tubulin and GAPDH loading control (panel A, left), and RT-PCR quantification of $\beta 3$-tubulin mRNA expression normalized to the $\mathrm{C}_{\mathrm{T}}$ values of RPL19 (panel A, right). (B) Naïve, control (ctrl)-, and $\beta 3$-tubulin siRNA-treated cells were immunostained with antibodies specific for $\beta 3$-tubulin (green) and MAA (orange), DAPI (blue) was used as nuclear DNA counterstain, original magnification $\times 630$ (bar, $20 \mu \mathrm{m})$. (C) MTT assay shows the effect of siRNA treatment on the cellular viability of A375 cells. Flow cytometric contour plots (D) and quantification (E) of MVs collected from the culture media of naïve, ctrl-, and $\beta 3$-tubulin-siRNA treated cells and immunostained with an MAA antibody or isotype control, plots illustrate the percentage of positively stained MVs ( $D$, red square gated events). Super-resolution microscopy with maximum intensity projection of a confocal stack micrographs of A375 cells (F), or MVs collected from culture media (G), stained with Alexa fluor 488-conjugated-WGA, red rectangles, in F and G, show randomly selected areas for higher magnification (right enlarged micrographs), illustrating ring-like microvesicles of varying sizes (200-1000 nm) with optically clear lumen. Original magnification $\times 1000$, scale bar $5 \mu \mathrm{m}$ (left graphs) or $1 \mu \mathrm{m}$ (magnified right graphs). Statistical significance was determined between different groups using an ANOVA with Tukey's correction for multiple comparisons. $n=5,{ }^{* * *} p<0.001$ versus naïve cells. 
(A)

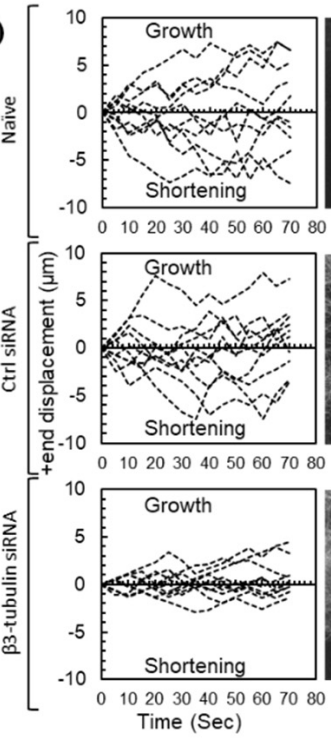

(B)

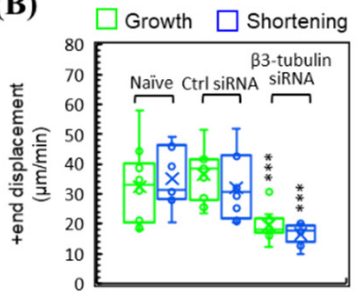

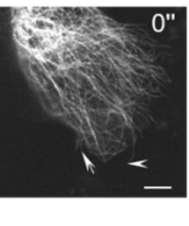
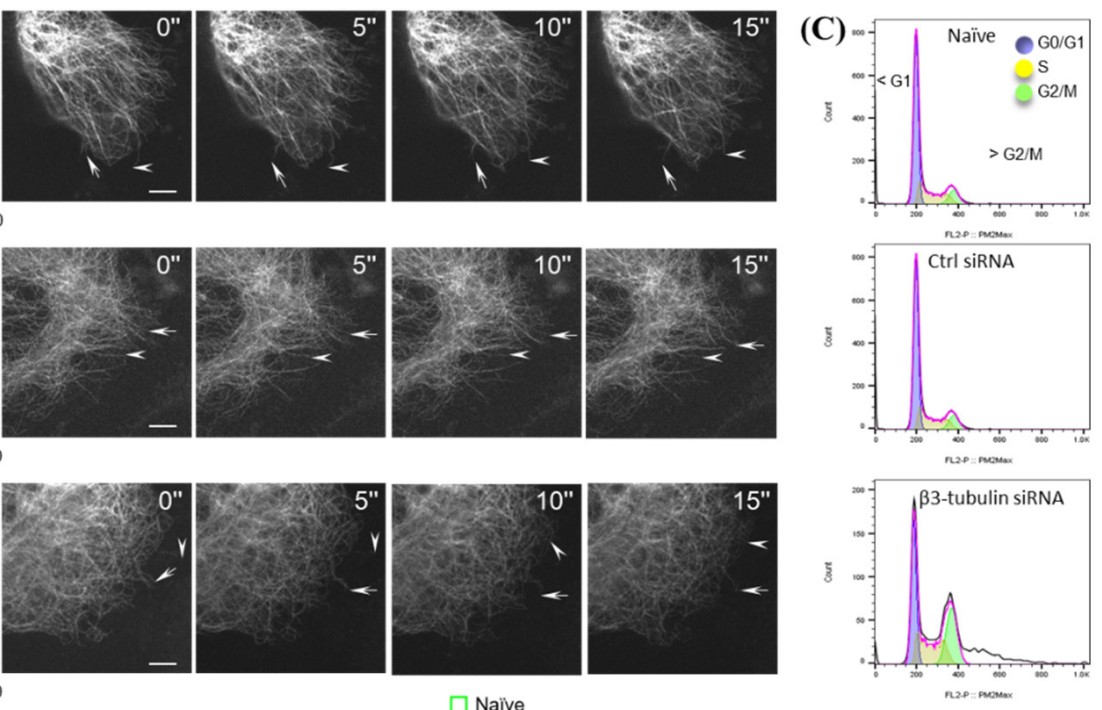

$\square$ Ctrl siRNA

$\square$ B3-tubulin siRNA
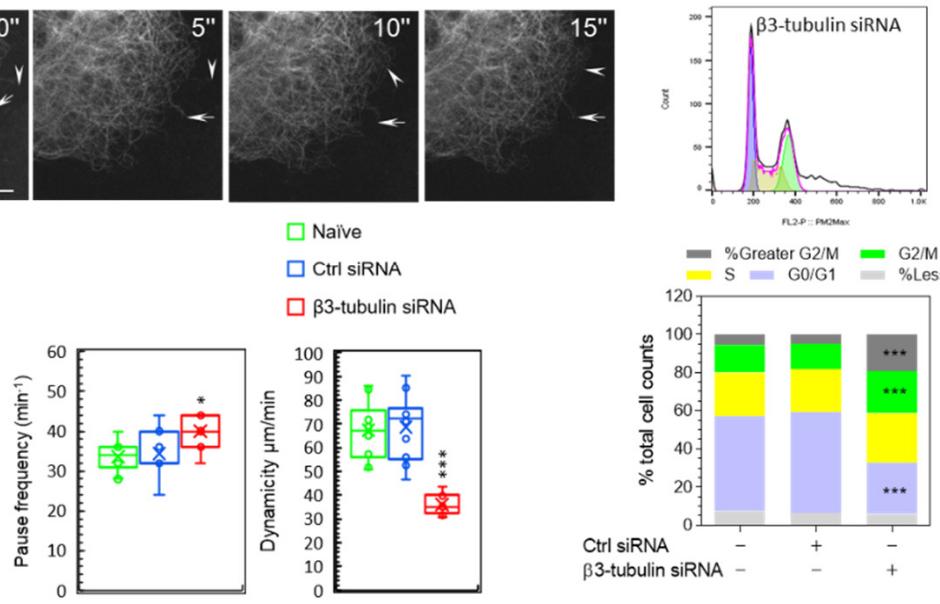
\%Greater G2/M
$\mathrm{S}=\mathrm{G} 0 / \mathrm{G} 1=$ G2/M
\%Less G0

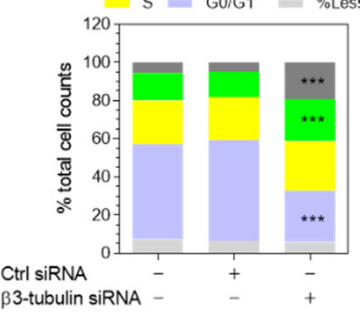

Figure 2. $\beta 3$-tubulin knockdown suppresses microtubules (MTs) dynamics and disrupts cell cycle in A375 cells. (Panel (A), right) Micrographs of EGFP-MAP-4-labeled MTs in naïve, ctrl-, and $\beta 3$-tubulin siRNA-treated A375 cells. Images were acquired every $5 \mathrm{~s}$ and show MTs +end growth (arrows) and shortening (arrowheads). Original magnification $\times 1000$ (bar, $5 \mu \mathrm{m}$ ). (panel (A) left) Traces of ten representative MTs +end displacements (growth and shortening) measured over a period of $75 \mathrm{~s}$. Quantification of dynamic growth and shortening (panel (B), left), and pause frequency (panel (B), middle) and dynamicity (panel (B), right). (C) Flow cytometric histograms (top panels), and cell cycle growth phase distribution analysis (bottom panel) demonstrate the effect of $\beta 3$-tubulin knockdown on cell cycle in A375 cells. Statistical significance between naïve, ctrl-, and $\beta 3$-tubulin-siRNA groups was determined using an ANOVA with Tukey's correction for multiple comparisons. $n=10$ (MTs analysis) or $=6$ (cell cycle analysis), ${ }^{* * *} p<0.001$, and ${ }^{*} p<0.05$ versus naïve cells.

Cell cycle analysis revealed that growth phase redistribution in $\beta 3$-tubulin knockdown cells as compared to naïve cells, where G2/M and polyploidy ( $>$ G2/M) cells were significantly increased by $53.12 \%(p<0.001)$ and $245.74 \%(p<0.001)$, respectively. Furthermore, G0/G1 cells were significantly reduced by $45.49 \%(p<0.001)$. Similar effects were not seen in control siRNA-treated cells. There was no significant change in the less than $\mathrm{G} 0(<\mathrm{G} 0)$ and S populations (Figure $2 \mathrm{C}$ and Figure S3).

\section{Discussion}

By understanding the mechanisms of carcinogenesis at the cellular and molecular level, current research focuses on targeting strategies for melanoma prevention and treatment. With essential regulatory roles in a myriad of inter- and intra-cellular activities, MTs dynamicity is an important target for many anti-cancer therapeutics [19-22]. $\beta$-tubulin is a structural protein that maintains the microtubule cytoskeleton. Distinct from the other six beta-tubulin isotypes in the human genome, $\beta 3$-tubulin has a unique molecular structure that facilitates its binding to factors involved in the oxidative stress and nutrient deprivation response, thereby bolstering the survival of stressed cells [23]. For example, induced expression of $\beta 3$-tubulin promotes resistance to the widely used chemotherapeutic 
agent, paclitaxel, in Hela and MCF-7 cell lines [24]. Furthermore, increased levels of $\beta 3$-tubulin expression have been linked to malignant transformation and migration of melanocytes [17]. In tandem with these studies, our Q-PCR, Western blot, and immunofluorescence data confirmed that $\beta 3$-tubulin was highly expressed in the human malignant melanoma cell line (A375).

To understand the relevance of $\beta 3$-tubulin on melanoma progression, we used siRNA to knockdown $\beta 3$-tubulin in the A375 cell line. We studied several factors known to contribute to metastasis and drug resistance, namely MVs release, MTs dynamics, and cell cycle regulation [19-22,25]. Our data demonstrated significant suppression of MTs dynamic parameters (e.g., growth, shortening, and pause frequencies), implying that $\beta 3$-tubulin is critical for MTs dynamicity. As normal MTs dynamics are essential for mitotic spindle formation and function, disrupting MTs dynamics would lead to the activation of the cell cycle checkpoints and force the malignant cells to initiate growth arrest and apoptotic cell death [26]. Despite the importance of $\beta$-tubulin isotypes in resistance to antimitotic drugs $[27,28]$, there are no studies to date examining the role of $\beta 3$-tubulin in cell cycle regulation in malignant melanoma. Thus, we investigated the effect of $\beta 3$-tubulin siRNA on the cell cycle in A375 melanoma cells, and the data demonstrated robust induction of G2/M arrest and a significant increase in polyploidy population in $\beta 3$-tubulin siRNA-treated cells. Such data provide direct evidence that $\beta 3$-tubulin alters melanoma cell cycle regulation. G2/M arrest, which may be the result of defective mitotic spindle formation, was shown to enhance the cytotoxic effect of chemotherapy in melanoma cell lines $[29,30]$. These results are consistent with previous work on Hela cells [31], where the reduction of $\beta 3$-tubulin expression by siRNA resulted in partial inhibition of cell growth. Interestingly, in H460 (non-small cell lung cancer), $\beta 3$ tubulin siRNA increased vincristine-and paclitaxel-induced suppression of microtubule dynamicity and cell death at low and high drug concentrations, respectively, while there was no effect on the G2/M population [32]; such data might propose varied and cell-specific roles of $\beta 3$ tubulin in different cell types.

Despite the importance of MVs as potential therapeutic targets in cancer (i.e., angiogenesis, matrix degradation and invasion, metastasis, and immunosuppression) and thrombosis [9,12,33], the mechanisms of their biogenesis and release remain poorly characterized. Several lines of evidence demonstrate that MVs are important for melanoma progression [13,14], coagulation [12], and inflammatory skin conditions (i.e., psoriasis) [34]. The correlation between MTs dynamics and MVs release was previously studied in mastocytoma P815 cell [35], where the authors demonstrated that microvesicle formation and shedding require MTs disruption. The role of MTs in controlling other cellular activities, such as movement and intracellular vesicle transportation was also reported [36,37]. However, the mechanisms of MVs biogenesis and release in melanoma cells remain controversial. Herein, we demonstrated that $\beta 3$-tubulin knockdown-induced repression of MTs dynamicity was associated with a reduction in the numbers of the MVs released by A375 cells, implying that $\beta 3$-tubulin may play a role in MVs production via regulating the MTs dynamics in melanoma cells. Further studies are required to elucidate the mechanistic role of the $\alpha$ - and $\beta$ - tubulins isotypes in the treatment and prevention of melanoma progression.

\section{Materials and Methods}

\subsection{Cell Culture EGFP-MAP-4 Transfection and siRNA Silencing}

A375 human malignant melanoma cells (ATCC ${ }^{\circledR}$ CRL-3224) were propagated in Dulbecco's Modified Eagle's Medium (DMEM—catalog no. 11995-065, Life Technologies, Grand Island, NY, USA) containing $4.5 \mathrm{~g} / \mathrm{L}$ D-glucose, L-glutamate, $110 \mathrm{mg} / \mathrm{L}$ sodium pyruvate, and supplemented with $10 \%$ fetal bovine serum (FBS-catalog no. 098105, MULTICEL) and 1\% penicillin-streptomycin (catalog no. 15140-122, Life Technologies). EGFP-MAP-4 transfection (provided by Dr. Joanna Olmsted, University of Rochester, USA) was performed as previously described [24]: briefly, cells were seeded in twelve-well plates at a density of 150,000 cells per well and transfected with $1 \mu \mathrm{g}$ plasmid DNA using lipofectamine 2000 (catalog no. P/N52887, Invitrogen, Carlsbad, CA, USA) following the manufacturer's instructions. 
Transfected cells were selected by growing in a growth medium containing G418, $2 \mathrm{mg} / \mathrm{mL}$ (catalog no. A1720; Sigma-Aldrich, Oakville, ON, Canada). For siRNA silencing, A375 cells were transfected with $25 \mathrm{nM}$ of $\beta 3$-tubulin siRNA (catalog no. sc-105009, Santa Cruz Biotechnology, Dallas, TX, USA) or FlexiTube Lamin A/C non-targeting siRNA (catalog no. SI03650332, Qiagen, Valencia, CA, USA), using transfection reagent lipofectamine RNAiMAX (catalog no. 13778-075, Thermo Fisher Scientific, Carlsbad, CA, USA) as per the manufacturer's protocol. Western analysis, RNA isolation, immunofluorescent microscopy, and MVs purification were performed $48 \mathrm{~h}$ after transfection, unless otherwise stated.

\subsection{RNA Isolation, $c D N A$ Synthesis, and $q P C R$}

Total RNA was extracted using NucleoSpin RNA purification kits (catalog no. 740955- 250, D-Mark Biosciences, Düren, Germany) and 500 ng was used for cDNA synthesis (qScript cDNA Synthesis kit, catalog no. CA101414-098, Quanta Biosciences, Gaithersburg, MD, USA). Real-time PCR (RT-PCR) was performed with a StepOne Plus PCR machine (Applied Biosystems, Foster City, CA, USA) using the fast SYBR Green master mix (catalog no. 4385618, Life Technologies). The amplification conditions were $95^{\circ} \mathrm{C}$ for $20 \mathrm{~s}$ followed by forty cycles at $95^{\circ} \mathrm{C}$ for $3 \mathrm{~s}$ and $60{ }^{\circ} \mathrm{C}$ for $30 \mathrm{~s}$. Primer sequences were as follows: $\beta 3$-tubulin, forward 5'-CGA AGC CAG CAG TGT CTA AA-3' , reverse 5'-GGA GGA CGA GGC CAT AAA TAC-3'; ribosomal protein L19 (RPL19), forward 5'-ATC GAT CGC CAC ATG TAT CA-3' ${ }^{\prime}$, reverse 5'-GCG TGC TTC CTT GGT CTT AG-3'.

\subsection{Electrophoresis, Western Analysis, and Fluorescent Microscopy}

Fifty micrograms of A375 melanoma cell lysate protein in radioimmunoprecipitation assay buffer (RIPA) containing 1\% of Halt ${ }^{\mathrm{TM}}$ protease inhibitor cocktail (catalog no.1861279, ThermoScientific) was separated by SDS-PAGE and transferred onto nitrocellulose membranes (catalog no. rpn203d, GE Health). Membranes were immunoprobed with rabbit monoclonal anti-human $\beta 3$-tubulin (catalog no. d71g9-xp, Cell Signaling), or mouse anti-human glyceraldehyde-3-phosphate dehydrogenase (GAPDH; catalog no. 4699-9555, Biogenesis). The secondary antibodies were peroxidase-conjugated goat anti-rabbit IgG (catalog no. 111-035-003, Jackson ImmunoResearch) and peroxidase-affini-pure goat anti-mouse IgG (catalog no. 115-035-003, Jackson ImmunoResearch). Immune complex visualization was carried out using ECL TM prime WB reagents (catalog no. rpn2232sk, GE Health). For fluorescence microscopy, A375 melanoma cells were fixed in pre-warmed culturing medium containing $3.7 \%$ formaldehyde (catalog no. f-8775, Sigma) for $15 \mathrm{~min}$ at $37^{\circ} \mathrm{C}$. Cellular and vesicular membranes were labeled with Alexa 488-conjugated wheat germ agglutinin (WGA, catalog no. W11261, Invitrogen) $5 \mu \mathrm{g} / \mathrm{mL}$ diluted in PBS for $10 \mathrm{~min}$ at room temperature followed by two washes in PBS. For cytoplasmic and inner membrane-bound protein immuno-detection, cells were permeabilized for $5 \mathrm{~min}$ at room temperature with $0.2 \%$ tween X-100 (catalog no. t9284, Sigma) in PBS and blocked for $1 \mathrm{~h}$ at room temperature using a blocking buffer (PBS containing 5\% albumin bovine serum, catalog no. a-4503, Sigma). The cells were probed with antibodies against $\beta 3$-tubulin, melanoma associated antigen (MAA, mouse monoclonal anti human, catalog no. ab34165, Abcam), isotype controls (rabbit IgG (monoclonal, catalog no. ab172730, Abcam), or mouse IgG 2b (catalog no. 557351, BD Pharmingen)) diluted in blocking buffer and incubated overnight at $4{ }^{\circ} \mathrm{C}$. The secondary antibodies used were rabbit Alexa fluor 488 goat anti-rabbit (catalog no. A11034, Invitrogen) and mouse Alexa fluor 555 goat anti-mouse (catalog no. A21424, Life technologies). 4',6-diamidino-2-phenylindole (DAPI, catalog no. d21490, Molecular probes) was used as a nuclear counterstain marker. Immunoprobed cells were mounted using prolong gold anti-fad reagent (catalog no. p36930, Invitrogen) and visualized by confocal microscopy and structured illumination super-resolution microscopy (Zeiss Elyria).

\subsection{MVs Purification and Flowcytometric Quantification}

MVs purification was carried out following the referenced protocol by Lima et al. [13]. Briefly, A375 melanoma cell culture supernatants were centrifuged at $800 \times g$ for 10 min to exclude floating 
dead cells and debris. Another centrifugation for $15 \mathrm{~min}$ at $14,000 \times g$ yielded a pellet, which was resuspended and recollected by repeat centrifugation (this and subsequent centrifugations were at $14,000 \times \mathrm{g}$ for $15 \mathrm{~min}$ at $4{ }^{\circ} \mathrm{C}$ ). The washed pellet containing MVs was suspended in $100 \mu \mathrm{L}$ ice-cold PBS. MVs were fixed by adding $900 \mu \mathrm{L}$ of $100 \%$ methanol at $-20^{\circ} \mathrm{C}$ dropwise with vigorous vortexing. This suspension was incubated at $-20^{\circ} \mathrm{C}$ for $5 \mathrm{~min}$ followed by the addition of $1 \mathrm{~mL}$ of ice-cold PBS. Fixed MVs were pelleted by centrifugation, resuspended in $250 \mu \mathrm{L}$ blocking buffer and incubated at room temperature for $1 \mathrm{~h}$. MVs were collected by centrifugation and immunostained overnight at $4{ }^{\circ} \mathrm{C}$ in $250 \mu \mathrm{L}$ of the blocking buffer containing a mouse monoclonal MAA antibody or mouse IgG $2 \mathrm{~b}$ isotype control at a concentration of $1 \mu \mathrm{g} / \mathrm{mL}$. MVs were then washed once in PBS, incubated one hour at room temperature in a blocking buffer containing Alexa fluor 488 goat anti-mouse (catalog no. a11001, Life Technologies) and washed once in PBS. MVs quantification was assessed using a flow cytometry (Guava ${ }^{\circledR}$ easyCyte; MilliporeSigma). Data analysis was carried out using FCS express 6 plus research edition software.

\subsection{Analysis of Microtubules Dynamics}

A375 cells were transfected with EGFP-MAP-4 (provided by Dr. Joanna Olmsted, University of Rochester, USA) as previously described [24]. MTs dynamics analysis was performed as previously published [38]: briefly, MTs +ends were tracked using Image software (Manual tracking plugin, https://imagej.nih.gov/ij/plugins/track/track.html). Only $0.5 \mu \mathrm{m}$ changes in growth/shortening traces were plotted for each MT. Any growth or shortening event below the $0.5 \mu \mathrm{m}$ threshold was considered a pause. The growth/shortening rate was calculated by dividing the sum of all growth (positive) or the sum of all shortening (negative) by the total time spent growing or shortening respectively. Pause frequencies were calculated by dividing the total number of pauses by the total measuring time. MTs dynamicity was extracted by dividing the sum of total length (growth and shortening) by the total measuring duration. Data was analyzed using GraphPad Prism 6, and MS-Excel software. Data Significances were calculated using a student $t$-test and one-way analysis of variants (ANOVA) with Tukey's correction for multiple comparison.

\subsection{Propidium Iodide (PI)-Staining and Cell Cycle Analysis}

A375 cells were fixed for $30 \mathrm{~min}$ in $70 \%$ ethanol at $4{ }^{\circ} \mathrm{C}$ and washed $2 \times$ in PBS. RNase $(100 \mu \mathrm{g} / \mathrm{mL})$ was added, and the cells were incubated for $20 \mathrm{~min}$ at $37^{\circ} \mathrm{C}$, followed with $2 \times$ washes in PBS. Cells were then incubated in $3 \mu \mathrm{M}$ PI (catalog no. p4170; Sigma) in the staining solution (100 mM tris, PH 7.4, $150 \mathrm{mM} \mathrm{NaCl}, 1 \mathrm{mM} \mathrm{CaCl}_{2}, 0.5 \mathrm{mM} \mathrm{MgCl}_{2}$, and $0.1 \%$ Nonidet P-40) for $15 \mathrm{~min}$ at room temperature. Cell cycle analysis was conducted using a flow cytometer (Guava ${ }^{\circledR}$ easyCyte; MilliporeSigma). Data analysis was carried out using FlowJo v10.6.1 software.

\section{Conclusions}

B3-tubulin knockdown suppresses MTs dynamics, decreases MVs release, and induces G2/M cell cycle arrest in human malignant melanoma cells (A375). $\beta 3$-tubulin, an important microtubular protein, may therefore be used to study the role of MTs and MVs in the pathogenesis and treatment of melanoma.

Supplementary Materials: Supplementary materials can be found at http://www.mdpi.com/1422-0067/21/5/1656/ s1.

Author Contributions: Research design: M.O.A., A.G., P.R.M., Conducted experiments and data acquisition: M.O.A., A.G., P.S., P.R.M., Contributed new reagent or analytical tool: S.S.L., G.J.L., M.A., Performed data analysis: M.O.A., A.G., G.J.L., S.S.L., M.A., P.R.M., Wrote or contributed to the drafting, writing and critically reviewing of the manuscript: M.O.A., A.G., G.J.L., M.A., S.S.L., P.S., P.R.M., Given final approval of the version to be published: M.O.A., P.R.M. All authors have read and agreed to the published version of the manuscript.

Funding: This research received no external funding. 
Acknowledgments: The authors gratefully acknowledge the support provided by Susanne V. Gibson and the Canadian Dermatology Foundation.

Conflicts of Interest: The authors declare no conflict of interest.

\section{Abbreviations}

$\begin{array}{ll}\text { MTs } & \text { Microtubules } \\ \text { MVs } & \text { Microvesicles } \\ \text { WGA } & \text { Wheat germ agglutinin } \\ \text { MAA } & \text { Melanoma associated antigen }\end{array}$

\section{References}

1. Katsetos, C.D.; Herman, M.M.; Mork, S.J. Class III beta-tubulin in human development and cancer. Cell Motil. Cytoskelet. 2003, 55, 77-96. [CrossRef] [PubMed]

2. Kueh, H.Y.; Mitchison, T.J. Structural plasticity in actin and tubulin polymer dynamics. Science 2009, 325, 960-963. [CrossRef]

3. Desai, A.; Mitchison, T.J. Microtubule polymerization dynamics. Annu. Rev. Cell Dev. Biol. 1997, $13,83-117$. [CrossRef] [PubMed]

4. Karp, G. Cell and Molecular Biology: Concepts and Experiments; John Wiley \& Sons: Hoboken, NJ, USA, 2005; p. 355.

5. Sugiyama, T.; Pramanik, M.K.; Yumura, S. Microtubule-Mediated Inositol Lipid Signaling Plays Critical Roles in Regulation of Blebbing. PLoS ONE 2015, 10, e0137032. [CrossRef] [PubMed]

6. Ganguly, A.; Yang, H.; Sharma, R.; Patel, K.D.; Cabral, F. The role of microtubules and their dynamics in cell migration. J. Biol. Chem. 2012, 287, 43359-43369. [CrossRef] [PubMed]

7. Knabbe, J.; Nassal, J.P.; Verhage, M.; Kuner, T. Secretory vesicle trafficking in awake and anaesthetized mice: Differential speeds in axons versus synapses. J. Physiol. 2018, 596, 3759-3773. [CrossRef]

8. Kobayashi, T.; Okamoto, H.; Yamada, J.-I.; Setaka, M.; Kwan, T. Vesiculation of platelet plasma membranes. Dilauroylglycerophosphocholine-induced shedding of a platelet plasma membrane fraction enriched in acetylcholinesterase activity. Biochim. Biophys. Acta 1984, 778, 210-218.

9. Théry, C.; Ostrowski, M.; Segura, E. Membrane vesicles as conveyors of immune responses. Nat. Rev. Immunol. 2009, 9, 581-593. [CrossRef]

10. Kunder, C.; John, A.L.S.; Li, G.; Leong, K.W.; Berwin, B.; Staats, H.F.; Abraham, S.N. Mast cell-derived particles deliver peripheral signals to remote lymph nodes. J. Exp. Med. 2009, 206, 2455-2467. [CrossRef]

11. Latifkar, A.; Hur, Y.H.; Sanchez, J.C.; Cerione, R.A.; Antonyak, M.A. New insights into extracellular vesicle biogenesis and function. J. Cell Sci. 2019, 132, jcs222406. [CrossRef]

12. Leroyer, A.; Anfosso, F.; Lacroix, R.; Sabatier, F.; Simoncini, S.; Njock, M.-S.; Jourde, N.; Brunet, P.; Camoin-Jau, L.; Sampol, J.; et al. Endothelial-derived microparticles: Biological conveyors at the crossroad of inflammation, thrombosis and angiogenesis. Thromb. Haemost. 2010, 104, 456-463. [CrossRef] [PubMed]

13. Lima, L.G.; Chammas, R.; Monteiro, R.Q.; Moreira, M.E.C.; Barcinski, M.A. Tumor-derived microvesicles modulate the establishment of metastatic melanoma in a phosphatidylserine-dependent manner. Cancer Lett. 2009, 283, 168-175. [CrossRef] [PubMed]

14. Laresche, C.; Pelletier, F.; Garnache-Ottou, F.; Lihoreau, T.; Biichlé, S.; Mourey, G.; Saas, P.; Humbert, P.; Seilles, E.; Aubin, F. Increased levels of circulating microparticles are associated with increased procoagulant activity in patients with cutaneous malignant melanoma. J. Investig. Dermatol. 2014, 134, 176-182. [CrossRef] [PubMed]

15. Wieckowski, E.U.; Visus, C.; Szajnik, M.; Szczepanski, M.J.; Storkus, W.; Whiteside, T.L. Tumor-derived microvesicles promote regulatory $\mathrm{T}$ cell expansion and induce apoptosis in tumor-reactive activated CD8+ T lymphocytes. J. Immunol. 2009, 183, 3720-3730. [CrossRef] [PubMed]

16. Muhsin-Sharafaldine, M.-R.; Saunderson, S.; Dunn, A.C.; Faed, J.M.; Kleffmann, T.; McLellan, A. Procoagulant and immunogenic properties of melanoma exosomes, microvesicles and apoptotic vesicles. Oncotarget 2016, 7, 56279-56294. [CrossRef] 
17. Orfanidis, K.; Wäster, P.; Lundmark, K.; Rosdahl, I.; Öllinger, K. Evaluation of tubulin beta-3 as a novel senescence-associated gene in melanocytic malignant transformation. Pigment Cell Melanoma Res. 2017, 30, 243-254. [CrossRef]

18. Rodrigues-Ferreira, S.; Molina, A.; Nahmias, C. Microtubule-associated tumor suppressors as prognostic biomarkers in breast cancer. Breast Cancer Res. Treat. 2019, 179, 267-273. [CrossRef]

19. Cirillo, L.; Gotta, M.; Meraldi, P. The Elephant in the Room: The Role of Microtubules in Cancer. Adv. Exp. Med. Biol. 2017, 1002, 93-124.

20. Dumontet, C.; Duran, G.E.; Steger, K.A.; Murphy, G.L.; Sussman, H.H.; Sikic, B.I. Differential expression of tubulin isotypes during the cell cycle. Cell Motil. Cytoskelet. 1996, 35, 49-58. [CrossRef]

21. Jordan, M.A.; Wilson, L. Microtubules as a target for anticancer drugs. Nat. Rev. Cancer 2004, 4, $253-265$. [CrossRef]

22. Dumontet, C.; Jordan, M.A. Microtubule-binding agents: A dynamic field of cancer therapeutics. Nat. Rev. Drug Discov. 2010, 9, 790-803. [CrossRef] [PubMed]

23. Cicchillitti, L.; Penci, R.; Di Michele, M.; Filippetti, F.; Rotilio, D.; Donati, M.B.; Scambia, G.; Ferlini, C. Proteomic characterization of cytoskeletal and mitochondrial class III beta-tubulin. Mol. Cancer 2008, 7, 2070-2079. [CrossRef] [PubMed]

24. Ganguly, A.; Yang, H.; Cabral, F. Class III beta-tubulin counteracts the ability of paclitaxel to inhibit cell migration. Oncotarget 2011, 2, 368-377. [CrossRef] [PubMed]

25. Parker, A.L.; Kavallaris, M.; McCarroll, J.A. Microtubules and their role in cellular stress in cancer. Front. Oncol. 2014, 4, 153. [CrossRef] [PubMed]

26. Jordan, M.A.; Kamath, K. How do microtubule-targeted drugs work? An overview. Curr. Cancer Drug Targets 2007, 7, 730-742. [CrossRef] [PubMed]

27. Bhattacharya, R.; Cabral, F. A ubiquitous beta-tubulin disrupts microtubule assembly and inhibits cell proliferation. Mol. Biol. Cell 2004, 15, 3123-3131. [CrossRef] [PubMed]

28. Burkhart, C.A.; Kavallaris, M.; Band Horwitz, S. The role of beta-tubulin isotypes in resistance to antimitotic drugs. Biochim. Biophys. Acta 2001, 1471, O1-O9.

29. Priebe, M.K.; Dewert, N.; Amschler, K.; Erpenbeck, L.; Heinzerling, L.; Schön, M.P.; Seitz, C.S.; Lorenz, V.N. c-Rel is a cell cycle modulator in human melanoma cells. Exp. Dermatol. 2019, 28, 121-128. [CrossRef]

30. Liu, J.; Jiang, G.; Mao, P.; Zhang, J.; Zhang, L.; Liu, L.; Wang, J.; Owusu, L.; Ren, B.; Tang, Y.; et al. Down-regulation of GADD45A enhances chemosensitivity in melanoma. Sci. Rep. 2018, 8, 4111. [CrossRef]

31. Shibazaki, M.; Maesawa, C.; Akasaka, K.; Kasai, S.; Yasuhira, S.; Kanno, K.; Nakayama, I.; Sugiyama, T.; Wakabayasi, G.; Masuda, T.; et al. Transcriptional and post-transcriptional regulation of betaIII-tubulin protein expression in relation with cell cycle-dependent regulation of tumor cells. Int. J. Oncol. 2012, 40, 695-702.

32. Gan, P.P.; McCarroll, J.A.; Po'Uha, S.T.; Kamath, K.; Jordan, M.A.; Kavallaris, M. Microtubule dynamics, mitotic arrest, and apoptosis: Drug-induced differential effects of betaIII-tubulin. Mol. Cancer 2010, 9, 1339-1348. [CrossRef] [PubMed]

33. Castellana, D.; Toti, F.; Freyssinet, J.M. Membrane microvesicles: Macromessengers in cancer disease and progression. Thromb. Res. 2010, 125 (Suppl. 2), S84-S88. [CrossRef]

34. Pelletier, F.; Garnache-Ottou, F.; Angelot, F.; Biichlé, S.; Vidal, C.; Humbert, P.; Saas, P.; Seilles, E.; Aubin, F. Increased levels of circulating endothelial-derived microparticles and small-size platelet-derived microparticles in psoriasis. J. Investig. Dermatol. 2011, 131, 1573-1576. [CrossRef] [PubMed]

35. Liepins, A. Possible role of microtubules in tumor cell surface membrane shedding, permeability, and lympholysis. Cell. Immunol. 1983, 76, 120-128. [CrossRef]

36. Downing, K.H.; Nogales, E. New insights into microtubule structure and function from the atomic model of tubulin. Eur. Biophys. J. 1998, 27, 431-436. [CrossRef]

37. Nogales, E. Structural insights into microtubule function. Annu. Rev. Biochem. 2000, 69, 277-302. [CrossRef]

38. Gierke, S.; Kumar, P.; Wittmann, T. Analysis of microtubule polymerization dynamics in live cells. Methods Cell Biol. 2010, 97, 15-33.

(C) 2020 by the authors. Licensee MDPI, Basel, Switzerland. This article is an open access article distributed under the terms and conditions of the Creative Commons Attribution (CC BY) license (http://creativecommons.org/licenses/by/4.0/). 